\title{
Role of microRNA-4458 in patients with non-small-cell lung cancer
}

\author{
LIDAO BAO ${ }^{1}$, LINLIN WANG ${ }^{2}$, GUOMIN WEI $^{2}$, YUEHONG WANG $^{3}$, GERILE WUYUN $^{3}$ and AGULA BO ${ }^{3}$ \\ ${ }^{1}$ Department of Pharmacy, Affiliated Hospital of Inner Mongolia Medical University, Hohhot, \\ Inner Mongolia 010059; ${ }^{2}$ Department of Respiration, Binzhou People's Hospital, Binzhou, Shandong 256610; \\ ${ }^{3}$ College of Mongolian Medicine, Inner Mongolia Medical University, Hohhot, Inner Mongolia 010110, P.R. China
}

Received January 31, 2015; Accepted March 1, 2016

DOI: $10.3892 / \mathrm{ol} .2016 .5176$

\begin{abstract}
Incidence and progression of non-small-cell lung cancer (NSCLC) is a multi-factor, multi-step process. The present study investigated the association between the expression level of microRNA (miR)-4458 in NSCLC and paracarcinoma liver tissues and survival rates, and studied the biological functions of miR-4458 at the cellular and protein level. NSCLC and paracarcinoma tissues were sequenced using a miR expression chip. The association between miR-4458 expression and tumor-node-metastasis staging, total survival rate and relapse-free survival rate was analyzed. miR-4458 was subjected to target gene prediction. The target protein of cyclin D1 (CCND1) was verified with western blot analysis, immunohistochemistry and a luciferase reporter assay. The relative level of $\mathrm{miR}-4458$ in paracarcinoma tissues of 9 NSCLC patients decreased from 2.38 to 0.65 $(\mathrm{P}<0.001)$. Total five-year survival rates of the high-expression miR-4458 group (29.21\%) significantly exceeded that of the low-expression group $(14.37 \%)(\mathrm{P}=0.025)$. The viability of human lung carcinoma A549 and H460 cells transfected with miR-4458 decreased significantly compared with cells transfected with a normal control (blank control plasmid) within $72 \mathrm{~h}(\mathrm{P}<0.001)$. The percentage of A549 and H460 cells transfected with a miR-4458 mimic at the cell cycle stage G0/G1 was $69.94 \pm 8.05$ and $68.15 \pm 7.75 \%$, respectively. The percentages increased significantly compared with the control group (46.06 \pm 6.93 for A549 cells; $45.22 \pm 7.24$ for H640 cells; $\mathrm{P}<0.001)$. CCND1 mRNA was downregulated significantly in $\mathrm{H} 460$ cells $72 \mathrm{~h}$ subsequent to the addition of miR-4458 mimics $(\mathrm{P}<0.001)$. The activity of mutant-CCND1 altered slightly, while the fluorescence intensity of the wild-type-CCND1 group decreased significantly following the addition of
\end{abstract}

Correspondence to: Professor Agula Bo, College of Mongolian Medicine, Inner Mongolia Medical University, 1 Jinshan Avenue, Hohhot, Inner Mongolia 010110, P.R. China

E-mail: bagulaimmu@163.com

Key words: non-small-cell lung cancer, miR-4458, cyclin D1, cancer suppressor gene
miR-4458 mimics. In conclusion, miR-4458 was expressed at low levels in lung cancer tissues, and it arrested cells in vitro at stage G0/G1 and inhibited cell proliferation. Therefore, miR-4458 may participate in the onset of lung cancer as a suppressor gene by inhibiting CCND1.

\section{Introduction}

An unstable genome is an important characteristic of cancer cells, and gene expression between cancerous and non-cancerous tissues is significantly different (1). Approximately one half of microRNA (miR) genes are distributed at unstable sites of the genome, including fragile sites of chromatin and cleavage sites $(2,3)$. There is a significant difference in the expression level of miRs in cancerous tissue and normal tissue (4). Based on their diversity and wide distribution throughout the genome, miRs may serve as an important tumor diagnostic method (5).

Lung cancer has the highest mortality rate worldwide at $92 \%$, and $80 \%$ of lung cancer cases are non-small-cell lung cancer (NSCLCs) (6). Although early-stage diagnostic techniques, chemotherapy and other targeted therapies are improving, the 5-year survival rate of NSCLC remains low at $6 \%$ (7). The incidence and progression of lung cancer is a multi-factor and multi-step complex process (8). Numerous miRs have roles as oncogenes or cancer suppressor genes in lung cancer cells, and there has been a great deal of investigation concerning the role of miRs in lung cancer; miR17-29 cluster, miR-31, miR-26a, miR-107, miR-185, miR-let-7 and miR-29a are all associated with the onset of lung cancer (9-15). These findings indicate that miRs are critical in the incidence and progression of lung cancer.

Currently, antitumor drugs specific to the cell cycle, including colchicine and taxol, demonstrate poor specificity to tumor cells and possess side-effects, including toxicity (16). In addition, antitumor drugs are liable to the development of drug resistance, which restricts clinical treatment (17). Therefore, treatment methods that target specific cell signaling pathways require investigation, and studies have identified novel targets for targeted therapy of tumor molecules, including the regulation of miRs $(18,19)$. Therefore, miRs provide a novel method for treating malignant tumors, and it has been observed that treating cancer by regulating the level of miRs in the 
cancerous cells is possible (20). The present study investigated miRs in human lung cancer and paracarcinoma tissue using the miRchip technique (21), and investigated if the expression levels of miRs were associated with lung cancer cells in vitro using quantitative polymerase chain reaction (qPCR). In addition, the present study investigated the biological functions of the potential target gene of miR-4458 in combination with cellular proliferation and cell cycle assays, and therefore preliminarily explained the role of miR-4458 in the onset of lung cancer.

\section{Materials and methods}

General data and patient tissue specimens. The present study selected 94 NSCLC patients with complete clinical and follow-up visit data, who underwent excision of NSCLC tissue at the Inner Mongolia Medical University (Hohhot, China) between January 2007 and June 2014. FOr each patient, specimens were taken of normal lung tissue from the lung cancer and normal paracarcinoma lung tissue (excised $5 \mathrm{~cm}$ from the edge of the tumor). No patient underwent radiotherapy or chemotherapy prior to surgery. The tissue was cryopreserved immediately following surgery, when all patients were pathologically diagnosed with NSCLC. All histological diagnoses were demonstrated by hematoxylin and eosin staining (Beyotime Institute of Biotechnology, Haimen, China). The information and specimen collection for all patients and the experiment specification were in accordance with standard operating procedures of the Ethics Committee of Inner Mongolia Medical University (Hohhot, China). The experimental content involving design of the medical ethics was approved by the Ethics Committee of the Inner Mongolia Medical University $(22,23)$. Written informed consent was obtained from all patients.

General characteristics of the patients. There were 94 patients that underwent NSCLC surgery, aged 49-86 years (median age, 54 years). There were 69 male patients $(73.4 \%)$ and 25 female patients (26.6\%). Tumor-node-metastasis (TNM) stages (24) for the patients was as follows: T1N0M0, 32 patients; T2N2M0, 25 patients; T2N0M0, 14 patients; T2N1M0, 11 patients; other stage, 12 patients. Histological stage: Ia, 17 patients; Ib, 13 patients; IIa, 20 patients; IIb, 9 patients; IIIa, 31 patients; and IV, 4 patients (25). The final follow-up appointment for all patients was on June 30, 2014.

Cell lines and culture. Human lung carcinoma A549 and H460 cell lines were purchased from Sinovac Biotech Ltd. (Shanghai, China), and human lung fibroblast HFL1 and human embryonic epithelial HEK293T cell lines were obtained from the Molecular Biology Experimental Center of Inner Mongolia Medical University (Hohhot, China). These two cells lines were cultured with Dulbecco's modified Eagle's medium (DMEM; Beyotime Institute of Biotechnology) containing $10 \%$ fetal bovine serum (Beyotime Institute of Biotechnology) in an atmosphere of $5 \% \mathrm{CO}_{2}$ at $37^{\circ} \mathrm{C}$. Cells in the logarithmic phase (rapidly growing for $24 \mathrm{~h}$ ) were used for the following experiments.

miR hybrid chip. The present study selected 15 patients from the original 94 patients at random. Total RNA was extracted from the lung cancer tissues using TRIzol ${ }^{\circledR}$ Reagent (Invitrogen $^{\mathrm{TM}}$; Thermo Fisher Scientific, Inc., Waltham, MA, USA), according to the manufacturer's protocol. The hybrid chip used in the present study was miRCURY ${ }^{\mathrm{TM}}$ LNA $^{\mathrm{TM}}$ microRNA Array kit (Exiqon, Vedbaek, Denmark). The chip used the Sanger microRNAs sequence database version 20.0 (www.mirbase.org/). An RNA fluorescent marker and chip hybridization was performed using the miRCURY ${ }^{\mathrm{TM}}$ LNA $^{\mathrm{TM}}$ microRNA Array Hi-Power Labeling kit (Exiqon). The marker enzyme Hy3TM fluorophore (Shanghai Biotechnology Corp., Shanghai, China) was used to mark the RNA for the chip hybridization fluorescence probe, according to the manufacturer's protocol. Each probe experiment was repeated 3 times. The green fluorescence signal was scanned with the Gene Pix 4000B Microarray Scanner (Molecular Devices LLC, Sunnyvale, CA, USA). The green fluorescence intensity was analyzed using Gene Pix Pro version 6.0 (Axon Instruments; Molecular Devices, LLC). The median value correction method was used to obtain the corrected value (26). The expression was regarded as upregulated if the ratio of the miR fluorescence corrected values of the NSCLC and paracarcinoma specimens was $\geq 1.5$. The expression was regarded as downregulated if the ratio of the miR fluorescence corrected values of the two specimens was $\leq 0.67$. The database miRGen version 3.0 (carolina.imis.athena-innovation.gr/index. php?r=mirgenv3) was used for bioinformatic analysis, which integrated various target prediction tools, including PicTar, miRanda, DIANA-micro $\mathrm{T}$ and Target Scan S. DAVID software version 2.4 (david.abcc.ncifcrf.gov/) was used for functional classification analysis of the target genes (27).

Detecting cellular proliferation using CellTiter. A549, H460 and HFLl cells in the logarithmic phase were selected, seeded in a 96-well microplate $\left(4 \times 10^{3}\right.$ cells/well; Beyotime Institute of Biotechnology) with DMEM containing $10 \%$ fetal bovine serum and placed in an incubator $\left(5 \% \mathrm{CO}_{2} ; 37^{\circ} \mathrm{C}\right)$ for culture overnight. The culture medium was discarded following $1 \mathrm{~h}$ of incubation. The cells were agitated for $10 \mathrm{~min}$ at room temperature following the addition of $35 \mu \mathrm{l}$ fresh culture medium and $35 \mu \mathrm{l}$ CellTiter 96 detection reagent (Promega Corporation, Madison, WI, USA). The cells (50 $\mu \mathrm{l})$ were transferred to an opaque white plate (Beyotime Institute of Biotechnology) at 24, 48 and $72 \mathrm{~h}$. The fluorescence value was tested using a fluorescence luminometer (F97Pro; Shanghai Lengguang Technology Co. Ltd, Shanghai, China). Relative proliferative activity $=$ appreciation rate of fluorescence value of treatment group / appreciation rate of fluorescence value of control group (28).

qPCR assay. Small RNAs (<100 nt) were extracted from the lung cancer cells and tissues using the Universal MicroRNA kit (Qiagen, Hilden, Germany). In total, $5 \mathrm{~g}$ tissue $=1 \mathrm{ml}$ water extract. Complementary (c)DNA was reverse transcribed using TaqMan MicroRNA Reverse Transcription kit (Applied Biosystems; Thermo Fisher Scientific, Inc.) on ice. The cDNA synthesis reaction mixture was $15 \mu \mathrm{l}$, which consisted of the following: $0.15 \mu \mathrm{l}$ dNTPs $(100 \mathrm{mM}), 1.00 \mu 1$ MultiScribe $^{\mathrm{TM}}$ Reverse Transcriptase, $1.50 \mu 1$ 10X Reverse Transcription Buffer, $0.19 \mu 1$ RNase Inhibitor, $4.16 \mu$ l nuclease-free water, $3 \mu \mathrm{l}$ hsa-miR-4458 or U6 5X RT Primer and $5 \mu$ l RNA sample 
(10 ng total RNA). Primers were synthesized by Shanghai Yanjing Biotechnology Co., Ltd (Shanghai, China). Primer Design software version 5 (PREMIER Biosoft, Palo Alto, CA, USA) and DNAMAN gene analysis software demo version 5.2.9 (Lynnon Biosoft, San Ramon, CA, USA) were used in order to detect the primer location and to screen the appropriate primers. The primer sequences were as follows: miR-4458, 5'-ACC TACAATGTGTGCTGGCTT TC-3'; miR-4458 inhibitor, 5'-GATCCCAGCAGCCAAGGCTAT GTTTCTACCGAAC-3'; and internal reference U6, 5'-CAC CACGTTTATACGCCGGTG-3'. The reaction conditions were $16^{\circ} \mathrm{C}$ for $30 \mathrm{~min}, 42^{\circ} \mathrm{C}$ for $30 \mathrm{~min}$, and $85^{\circ} \mathrm{C}$ for $5 \mathrm{~min}$. The cDNA synthesized by reverse transcription was stored at $-20^{\circ} \mathrm{C}$ for later use. A relative $\mathrm{qPCR}$ analysis was conducted with $\mathrm{U} 6$ as the internal reference. The PCR reaction occurred in a qPCR amplifier (Quantstudio ${ }^{\mathrm{TM}}$ DX Real-Time PCR Instrument; Thermo Fisher Scientific, Inc.). The reaction mixture was $20 \mu \mathrm{l}$ and consisted of the following: $1.33 \mu \mathrm{l}$ cDNA, $1 \mu \mathrm{l}$ hsa-miR-4458, or U6 20X Real Time primer, $10 \mu$ l TaqMan 2X Universal PCR Master Mix and 7.67 $\mu$ l nuclease-free water, taken from the Platinum ${ }^{\circledR}$ Quantitative PCR SuperMix (Invitrogen; Thermo Fisher Scientific, Inc.). The reaction conditions were $95^{\circ} \mathrm{C}$ for $10 \mathrm{~min}, 95^{\circ} \mathrm{C}$ for $15 \mathrm{sec}$ and $60^{\circ} \mathrm{C}$ for $1 \mathrm{~min}$ for a total of 40 cycles (29). qPCR data analysis was performed using Sequence Detection System version 2.3 software (ABI PRISM $^{\circledR} 7900$ HT; Applied Biosystems; Thermo Fisher Scientific, Inc.). The expression level of miRs was expressed using the $\Delta \mathrm{Cq}$ value ( $\mathrm{Cq} \mathrm{miR}$ relative to $\mathrm{Cq} \mathrm{U6}$ ) (30). Each experiment was repeated 3 times.

Plasmid cell transfection. miR-4458 mimic and inhibitor and miR-Scramble were synthesized by miR-Ribo (Guangzhou RiboBio Co., Ltd., Guangzhou, China). The sequences were as follows: miR-4458 mimic, 5'-AGAGGUAGGUGUGGA AGAA-3'; miR-4458 inhibitor, 5'-UCGCACUGCUAGCUA CGCUAGC-3'; miR-Scramble, 5'-CGAGUAGACUCCAAC UGUGAUC-3'. The miRs were transfected into plasmids, and these plasmids were transfected into A549 and H460 cells. The A549 and H460 cells were cultured for $24 \mathrm{~h}$ in a 24-well microplate $\left(5 \times 10^{4}\right.$ cells/well $)$ prior to transfection. The cell transfection process was in accordance with the manufacturer's protocol for Oligofectamine ${ }^{\mathrm{TM}}$ Transfection Reagent (Invitrogen; Thermo Fisher Scientific, Inc.). miRs were transfected into riboFECT ${ }^{\mathrm{TM}} \mathrm{CP}$ plasmids (Guangzhou RiboBio Co., Ltd.). DMEM was added to each well at $4 \mathrm{~h}$ following transfection. The cells were cultured for 48 and $72 \mathrm{~h}$ at $37^{\circ} \mathrm{C}$ in an atmosphere of $5 \% \mathrm{CO}_{2}$. The experiment included a negative control (miR-Scramble), blank control (no miR mimic) and lipidosome (Guangzhou RiboBio Co., Ltd.) groups with 3 duplicated wells for each group.

Luciferase reporter gene experiment. The 3'-UTRs of CCND1 were amplified by PCR using the following primers: 5'-GTACTGGAGAATGTGCCCTGCGGCA-3' and 5'-AGCTCGAGTAAGGCTCTGCACCCGC-3' (Primer Premier version 6.0; PrimerDesign Ltd., Chandler's Ford, UK). MUT-CCND1-3'UTR was designed to completely inhibit the 9 consistent base sequences of miR-4458 and WT-CCND1-3'UTR. DNAMAN gene analysis software demo version 5.2.9 was used to identify the consistent base sequences.
The luciferase reporter vector pGL3M-CCND1-3'UTR (50 ng) (Promega Corporation) and the control plasmid pcDNA3.1 (10 ng) (GeneCopoeia, Inc., Rockville, MD, USA) were co-transfected into 293T cells using Lipofectamine ${ }^{\circledR} 2000$ Reagent (Thermo Fisher Scientific, Inc.) and the lipidosome mediation transfection method (31). The cells were named the experimental group pGL3M-WT-CCND1-3'UTR, positive control group pGL3M-MUT-CCND1-3'UTR and negative control group pGL3 $\mathrm{M}$. The PCR products were then inserted into pGL3-basic vector. Target site mutations were generated using the PCR products with the appropriate primers containing point substitutions (MUT-CCND1 5'-GUUGCU GCAACACAACUAUAUAU-3'). The sequences were verified by DNA sequencing. HEK293T cells were co-transfected with $0.1 \mathrm{mg}$ reporter plasmid with $0.65 \mathrm{pmol}$ miRNA mimic or control miRNA in 96-well plates. Luciferase activity was detected $48 \mathrm{~h}$ later using a dual-luciferase reporter assay system and normalized to Renilla activity.

Investigating the cell cycle using flow cytometry. A549 and H460 cells were digested with pancreatic enzymes (Beytime Institute of Biotechnology) to obtain a cell suspension (following culturing for $48 \mathrm{~h}$ at $37^{\circ} \mathrm{C}$ in an atmosphere of $5 \%$ $\mathrm{CO}_{2}$ ), washed with phosphate-buffered saline (PBS; Beyotime Institute of Biotechnology) and resuspended in $700 \mu \mathrm{l}$ ethanol and $300 \mu 110 \%$ fetal bovine serum. The cells were mixed with $1 \mathrm{ml}$ of $-20^{\circ} \mathrm{C}$ absolute ethyl alcohol (Beyotime Institute of Biotechnology) and fixed at $4^{\circ} \mathrm{C}$ overnight using P0020 fixing reagent (Beyotime Institute of Biotechnology). The cells were centrifuged at $560 \mathrm{x}$ g for $5 \mathrm{~min}$, washed once or twice with PBS following discarding of the ethanol and resuspended in PBS. Following addition of the PBS staining solution containing propidium iodide (PI; final concentration, $50 \mu \mathrm{g} / \mathrm{ml}$; Beyotime Institute of Biotechnology) and RNase A (final concentration $100 \mu \mathrm{g} / \mathrm{ml}$; Shanghai Biotechnology Corp.), the cells were stained for $1 \mathrm{~h}$ in the dark. Subsequently, the cells were detected using the MoFlo ${ }^{\circledR}$ Astrios $^{\mathrm{TM}}$ EQ Flow Cytometer (Beckman Coulter, Inc., Bream, CA, USA) (29). The experiment was repeated 3 times.

Investigating CCND1 protein expression using western blot analysis. A549 and H460 cells were transferred to a centrifugal tube. The cells were subjected to protein extraction (ProteoPrep ${ }^{\circledR}$ Total Extraction Sample kit; Sigma-Aldrich, St. Louis, MO, USA) and quantification in accordance with the manufacturer's protocol. Subsequently, $30 \mu \mathrm{g}$ protein underwent $10 \%$ sodium dodecyl sulfate-polyacrylamide gel electrophoresis. The gel was electrotransferred onto a polyvinylidene difluoride (PVDF) membrane and blocked in 5\% skim milk powder for $2 \mathrm{~h}$ at room temperature. The blocked PVDF membrane was placed in the primary antibody (rabbit anti-CCND1 polyclonal antibody; dilution, 1:200; catalog no., BA0873; Boster Wuhan Biological Engineering, Co., Ltd., Wuhan, China) solution diluted with Tris-HCl-buffered saline and Tween (TBST) and slowly agitated at $4^{\circ} \mathrm{C}$ overnight. The membrane was washed at room temperature with western wash buffer (Beyotime Institute of Biotechnology). The PVDF membrane was incubated with secondary antibodies (fluorescein isothiocyanate-conjugated donkey anti-rabbit; dilution, 1:200; catalog no., 711-475-152; and cyanine 3-conjugated 
donkey anti-rabbit; dilution, 1:200; catalog no., 711-475-205; Jackson Immuno Research Laboratories, Inc., West Grove, PA, USA) diluted with TBST $(1: 10,000)$ for $2 \mathrm{~h}$ at room temperature. Enhanced chemiluminescence X-ray imaging (Beyotime Institute of Biotechnology) was used to detect the signals. The signal intensity was subject to a relative quantitative analysis using imaging analysis software (Image-Pro Plus version 6; Media Cybernetics, Rockville, MD, USA). The gel analysis was expressed with integrated optical density value. All reagents for the western blot were purchased from Sigma-Aldrich.

Immunohistochemistry. The patient tissue specimens were fixed in $4 \%$ formaldehyde (Beyotime Institute of Biotechnology) at $4^{\circ} \mathrm{C}$, embedded in paraffin (Beyotime Institute of Biotechnology), sectioned (5 $\mu \mathrm{m}$ thickness) with a paraffin slicing machine (YD-202A; Zhengzhou Nanbei Instrument Equipment Co., Ltd., Zhengzhou, China), dried in an incubator at $37^{\circ} \mathrm{C}$, subjected to antigen retrieval following dewaxing with xylene (Beyotime Institute of Biotechnology), blocked in 5\% bovine serum albumin (diluted with PBS; Beyotime Institute of Biotechnology), incubated with primary antibody (rabbit polyclonal CCND1 antibody; dilution, 1:200; Leica Microsystems $\mathrm{GmbH}$, Wetzlar, Germany) at $4^{\circ} \mathrm{C}$ overnight followed by washing with PBS 3 times for $3 \mathrm{~min}$ each. The sections were subsequently incubated with goat IgG secondary antibody (dilution, 1:200; Leica Microsystems $\mathrm{GmbH}$ ) for $30 \mathrm{~min}$ at room temperature, washed with PBS 3 times for 3 min each and stained with the color reagent 3,3'-diaminobenzidine, followed by rinsing in water and counterstaining with hematoxylin (Beyotime Institute of Biotechnology). A CX31-LV320 light microscope (Olympus Corp., Tokyo, Japan; magnification, $\mathrm{x} 400$ ) was used to observe the samples.

Statistical analysis. The miR chip expression profile used the SAM and TIGR Multiple Array Viewer version 4.0 software (www.tm4.org/index.html) for analysis. The data were expressed as the mean \pm standard deviation. Inter-group differences were subject to Student's t-test. Inter-group enumeration data were compared with the $\chi^{2}$ test or Fisher's exact probability method. $\mathrm{P}<0.05$ was considered to indicate a statistically significant difference. $\mathrm{P}<0.01$ was considered to indicate a distinctively statistically significant difference. SPSS version 18.0 software (SPSS, Inc., Chicago, IL, USA) was used for statistical analysis.

\section{Results}

Expression of miR-4458 in NSCLC and paracarcinoma tissues. Based on the chip data, it was observed that there was a significant difference in the expression of $58 \mathrm{miRs}$ in 15 pairs of NSCLC and paracarcinoma tissues (upregulated/downregulated, >1.5 times; Fig. 1A). There were differences in 26 miRs in the NSCLC tissue compared with the paracarcinoma tissue with variation $>2$ times, and 20 downregulated and 6 upregulated miRs (Fig. 1B). miR-4458 had the most significant alteration in its expression level between NSCLC and paracarcinoma tissue (0.27 times in the paracarcinoma tissue). qPCR was conducted to investigate the miR-4458 expression level in 94 patients with NSCLC. It was demonstrated that the median expression level of miR-4458 in the paracarcinoma tissue of the 94 patients decreased from 2.38 to 0.65 ( $\mathrm{P}<0.001$; Fig. 1C). The median downregulation of miR-4458 expression in the 94 patients between non-cancerous and cancerous tissue was 0.65 , and the patients were divided into two groups based on this cut-off value: miR-4458 low-expression group (52 patients) and miR-4458 high-expression group (42 patients). The 1, 2, 3, 4 and 5-year total survival rates were 72.6, 48.2, 28.9, 16.1 and $14.4 \%$, respectively, in the miR-4458 low-expression group, compared with $69.7,51.5,44.9,32.2$ and $29.1 \%$, respectively, in the miR-4458 high-expression group ( $\mathrm{P}=0.025$; Fig. 1D). The 1, 2, 3, 4 and 5-year relapse-free survival rates were 58.8, 33.9, $13.4,7.8$ and $7.8 \%$, respectively, in the miR-4458 low-expression group, compared with 70.6, 38.2, 34.4, 21.3 and $17.6 \%$ in the miR-4458 high-expression group ( $\mathrm{P}=0.019$; Fig. 1E).

Association of expression of $\mathrm{miR}-4458$ in lung carcinoma cell lines and cell proliferation. To study the biological functions of miR-4458, the present study initially investigated the expression of miR-4458 in human lung carcinoma A549 and H460 cell lines and the human lung fibroblast HFL1 cell line. The results demonstrated that the expression level of miR-4458 in A549 and H460 cell lines was downregulated significantly compared with normal HFL1 cells $(\mathrm{P}=0.017$; Fig. 2A). The expression level of miR-4458 in the A549 and H460 cell lines increased significantly compared with HFL1 cells $(\mathrm{P}<0.001$; Fig. 2B). Therefore, transfection of cells with miR-4458 mimics was able to successfully increase the expression of endogenous miR-4458.

The normal lung HFL1 cells were first transfected with the miR-4458 inhibitor. A CellTiter kit was used to detect the cell proliferation at 24, 48 and $72 \mathrm{~h}$. There was no difference in cell proliferation within the initial $48 \mathrm{~h}$ (data not shown). The proliferation of the cells transfected with the miR-4458 inhibitor was increased compared with the cells transfected with the negative control miRNA (NC) at $72 \mathrm{~h}(\mathrm{P}=0.025$; Fig. $2 \mathrm{C})$. To additionally verify the effect of miR-4458 on cellular proliferation, A549 and H460 cells were transfected with miR-4458 and NC. Fig. 2D and E demonstrates that the A549 and H460 cells transfected with miR-4458 proliferated slowly compared with NC. There was no difference in cellular proliferation within the initial $24 \mathrm{~h}$. The cells transfected with NC proliferated significantly more at $48 \mathrm{~h}$ compared with the cells transfected with miR-4458 $(\mathrm{P}=0.011)$. The viability of the cells transfected with miR-4458 decreased significantly compared with that of the cells transfected with NC $(\mathrm{P}<0.001)$. Therefore, miR-4458 was able to inhibit cellular proliferation in A549 and H460 cells.

miR-4458 arrests lung carcinoma at cell cycle stage G0/G1. Inhibition of cellular proliferation indicated the possibility of miR-4458 inhibiting the cell cycle. Therefore, the present study investigated the distribution of various phases of the cells using flow cytometery. The cell cycle was analyzed using PI-stained DNA. A549 cells transfected with miR-4458 mimics at stage G0/G1 accounted for $69.94 \pm 8.05 \%$. H460 cells at stage $\mathrm{G} 0 / \mathrm{G} 1$ accounted for $68.15 \pm 7.75 \%$ (Fig. 3A and B). These percentages were increased significantly compared with the control group $(\mathrm{P}<0.001)$. The percentage of A549 cells at stage $\mathrm{S}$ was significantly decreased compared with the control cells $(\mathrm{P}=0.028)$, and the growth rate of $\mathrm{H} 460$ cells was also observed to have slowed down. A549 and H460 cells at 
A

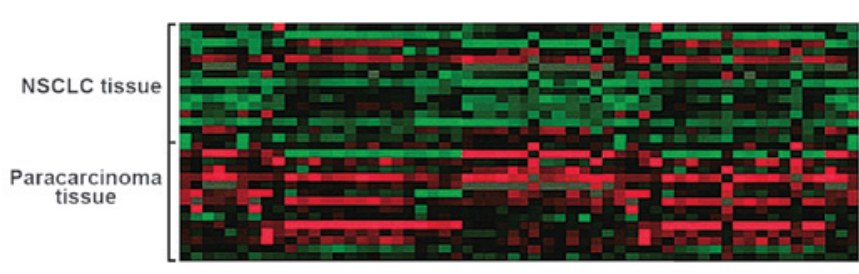

C

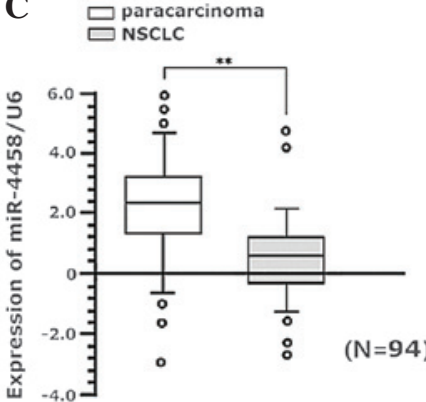

B

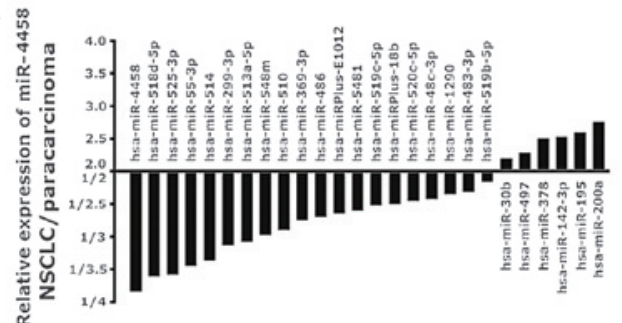

$\mathbf{E}$

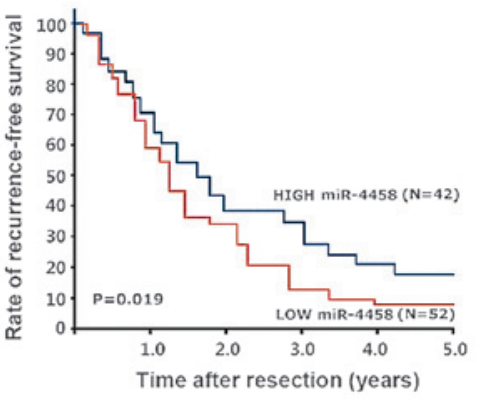

Figure 1. (A) miR chip analysis demonstrated that there was a significant difference in the expression of 58 miRs in 15 pairs of NSCLC and paracarcinoma tissues (variation $>1.5$ times). (B) Compared with the paracarcinoma tissue, there were 26 miRs (downregulated, 20; upregulated, 6) in NSCLC tissue with variation $>2$ times. (C) Quantitative polymerase chain reaction was conducted to investigate the miR-4458 level of 94 patients with NSCLC (U6 used as the internal reference). The level of miR-4458 in the cancerous tissue was significantly reduced compared with the paracarcinoma tissue $(\mathrm{P}<0.001)$. (D and E) The patients were divided into miR-4458 low-expression group (52 patients) and miR-4458 high-expression group (42 patients), based on the average downregulation of miR-4458 as a division point (0.65). (D) The 1,2,3,4 and 5-year overall survival rates in the miR-4458 low-expression group and high-expression group $(\mathrm{P}=0.025)$ and $(\mathrm{E})$ the 1, 2,3,4 and 5-year relapse-free survival rates in the miR-4458 low-expression and high-expression groups $(\mathrm{P}=0.019)$. miR, microRNA; NSCLC, non-small cell lung cancer.

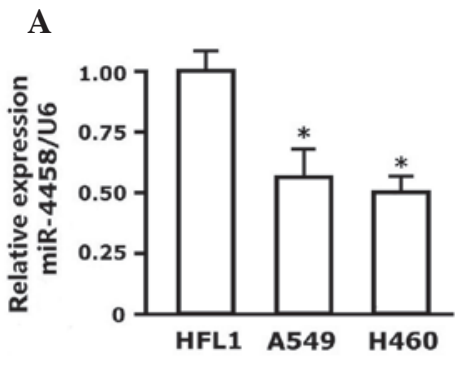

C

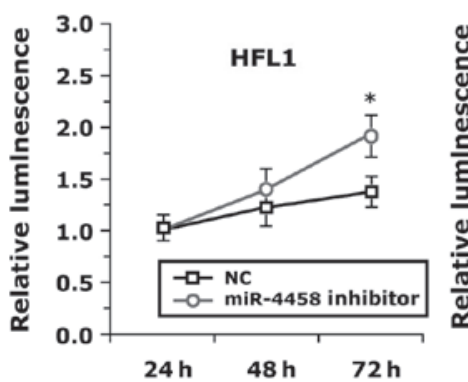

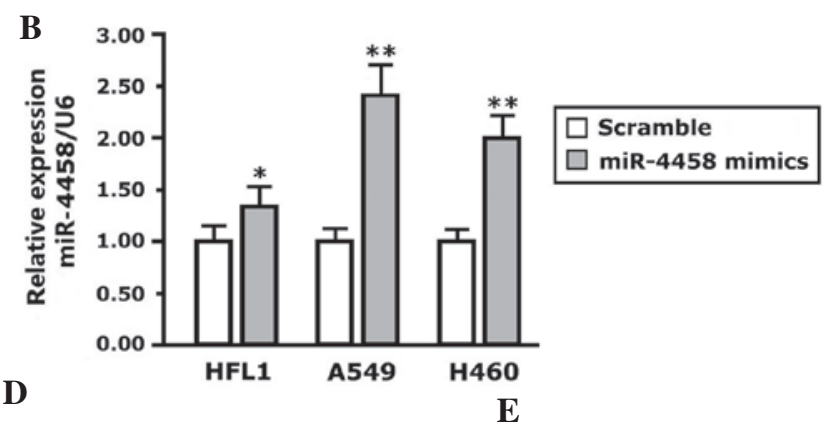
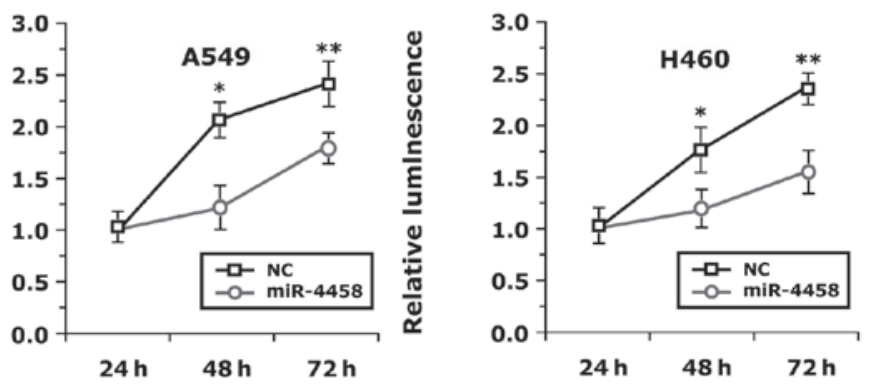

Figure 2. (A) Quantitative polymerase chain reaction was used to detect the expression of miR-4458 in human lung carcinoma A549 and H460 cell lines and human lung fibroblast HFL1 cell line. Compared with the normal HFL1 cells, the expression level of miR-4458 in the A549 and H460 cells was significantly downregulated ("P<0.05). (B) Compared with the control group, the expression levels of miR-4458 in HFL1, A549 and H460 cells transfected with miR-4458 mimics were significantly increased compared with cells transfected with scramble miR $\left({ }^{*} \mathrm{P}<0.05 ;{ }^{* *} \mathrm{P}<0.001\right)$. (C) Cell proliferation was detected with CellTiter. The normal HFL1 cells were transfected with miR-4458 inhibitor. The viability of the cells transfected with the miR-4458 inhibitor was increased compared with cells transfected with NC (significantly increased at $72 \mathrm{~h},{ }^{*} \mathrm{P}<0.05$ ). (D and E) A549 and H460 cells were transfected with miR-4458. The cells transfected with miR-4458 proliferated significantly at $48 \mathrm{~h}$ compared with cells transfected with $\mathrm{NC}$ ("P<0.05). The viability of the cells transfected with miR-4458 decreased significantly compared with cells transfected with $\mathrm{NC}$ at $72 \mathrm{~h}\left({ }^{* * *} \mathrm{P}<0.01\right)$. miR, microRNA; NC, normal control.

stage G2/M were significantly decreased compared with the control group $(\mathrm{P}<0.001)$. There were more A549 and H460 miR-4458-transfected cells at stage G0/G1.
miR-4458 is capable of inhibiting CCND1 protein expression in human NSCLC cells. Western blot analysis indicated that there was no significant alteration in the levels of CCDN1 
A
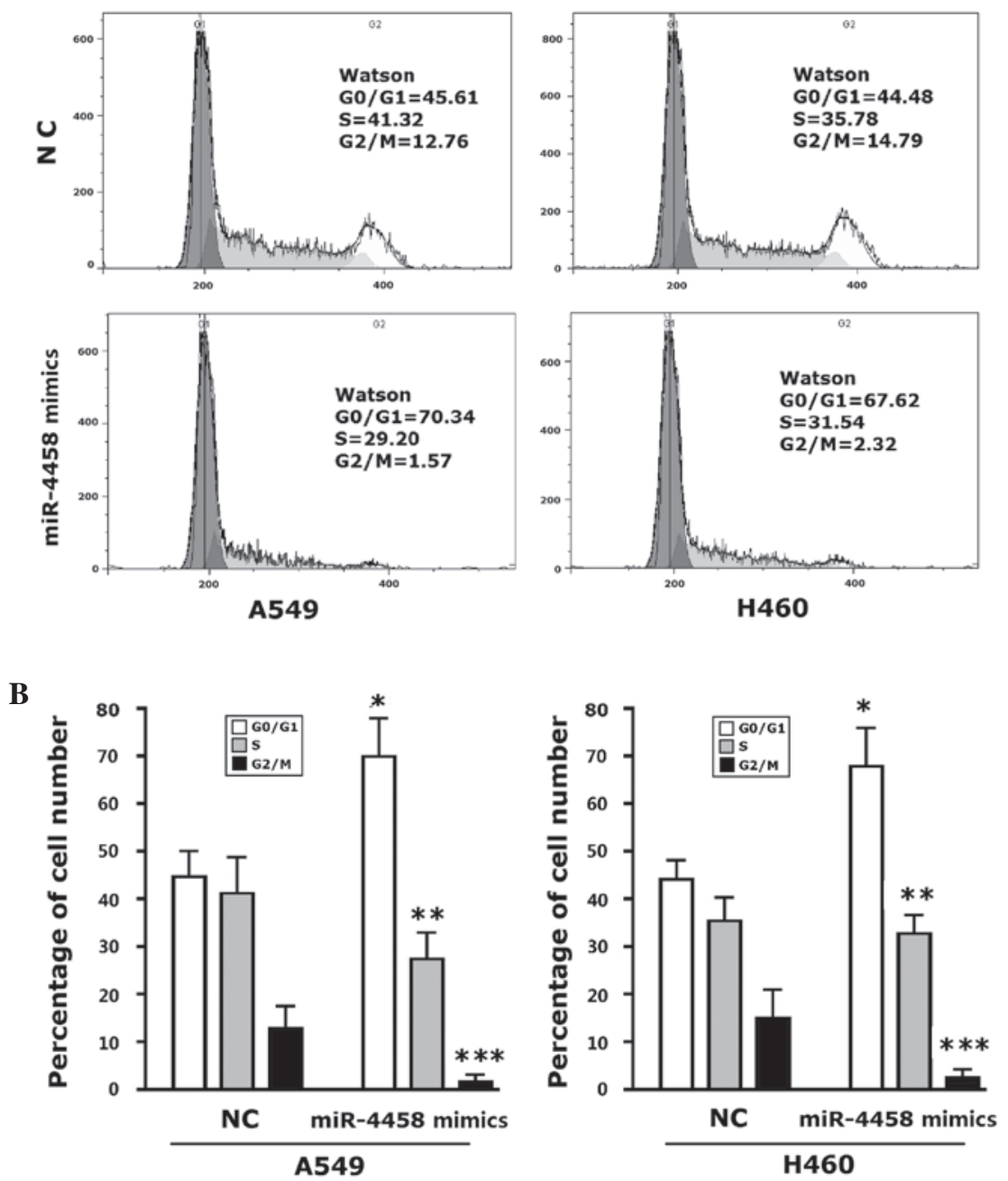

Figure 3. Distribution of various stages of the cell cycle was detected in human lung carcinoma A549 and H460 cells using flow cytometry. DNA stained with propidium iodide was used to analyze the cell cycle. (A) Cell cycle arrest occurred in the cells transfected with miR-4458, shifting them between stage G0/G1 and stage $\mathrm{S}$. The majority of cells were arrested at stage G0/G1. (B) Left panel: The percentage of A549 cells transfected with miR-4458 mimics at stage G0/G1 increased significantly, while those at stage S decreased significantly compared with cells transfected with NC. Right panel: The percentage of H460 cells transfected with miR-4458 mimics at stage G0/G1 increased significantly, while those at stage S decreased significantly compared with cells transfected with $\mathrm{NC}\left({ }^{*} \mathrm{P}<0.05 ;{ }^{* *} \mathrm{P}<0.01 ;{ }^{* * *} \mathrm{P}<0.001\right) . \mathrm{miR}$, microRNA; NC, normal control.

$24 \mathrm{~h}$ subsequent to the addition of A549 and H460 cells to miR-4458 mimics. CCND1 protein expression was downregulated at $48 \mathrm{~h}$. CCND1 protein expression was significantly downregulated at $72 \mathrm{~h}(\mathrm{P}<0.001$; Fig. $4 \mathrm{~A}$ and $\mathrm{B})$. The present study observed the expression of CCND1 protein in lung cancer tissue and paracarcinoma tissue of lung cancer patients using immunohistochemistry. The expression level of CCND1 in lung cancer tissues was increased compared with the paracarcinoma tissue (Fig. 4C). Therefore, miR-4458 was capable of inhibiting the expression of CCND1 in lung cancer tissue.

miR-4458 had 9 sequences completely consistent with WT-CCND1-3'UTR (Fig. 5A). After MUT-CCND1 was used to generate target site mutations at the seed sequence, the reporter result of the luciferase assay conducted in $293 \mathrm{~T}$ cells indicated that there were no significant changes in pGL3M-MUT-CCND1-3'UTR and pGL3M-WT-CCND1-3'UTR in the negative control group compared with pGL3M in the vacant plasmid group. There were no significant changes in viability of the cells in the MUT group while the fluorescence intensity in the WT group decreased significantly following the addition of miR-4458 mimics (Fig. 5B; $\mathrm{P}<0.001$ ). These results indicate that miR-4458 was capable of binding with the specific sequence in the promoter of WT-CCND1-3'UTR. miR-4458 did not function following an alteration in the specific sequence of the promoter.

\section{Discussion}

There have been numerous studies concerning the gene expression difference between cancerous and non-cancerous cells, and they have demonstrated that metabolic signaling pathways alter as a result of the difference in cancerous cells and normal physiological processes (32). miRs are diverse and are widely distributed in the genome; therefore, alterations in the genomes of cancerous cells may be observed by studying alterations in the expression of miRs (33). Consequently, miRs are molecules that may serve as diagnostic markers for cancers.

The present study demonstrated that there is a low expression of miR-4458 in lung cancer tissue based on the difference 

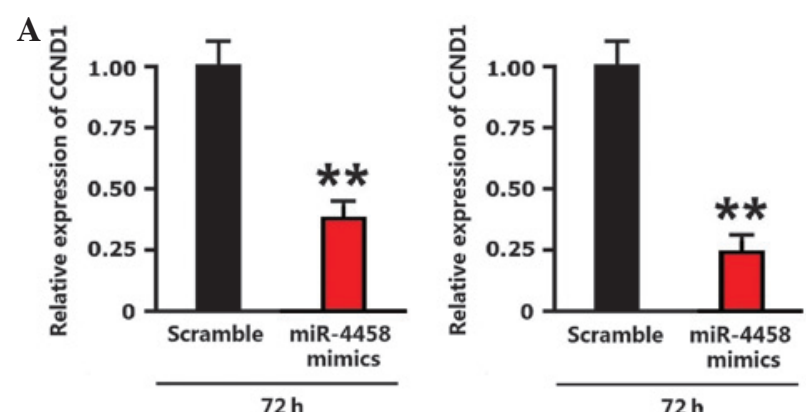

B
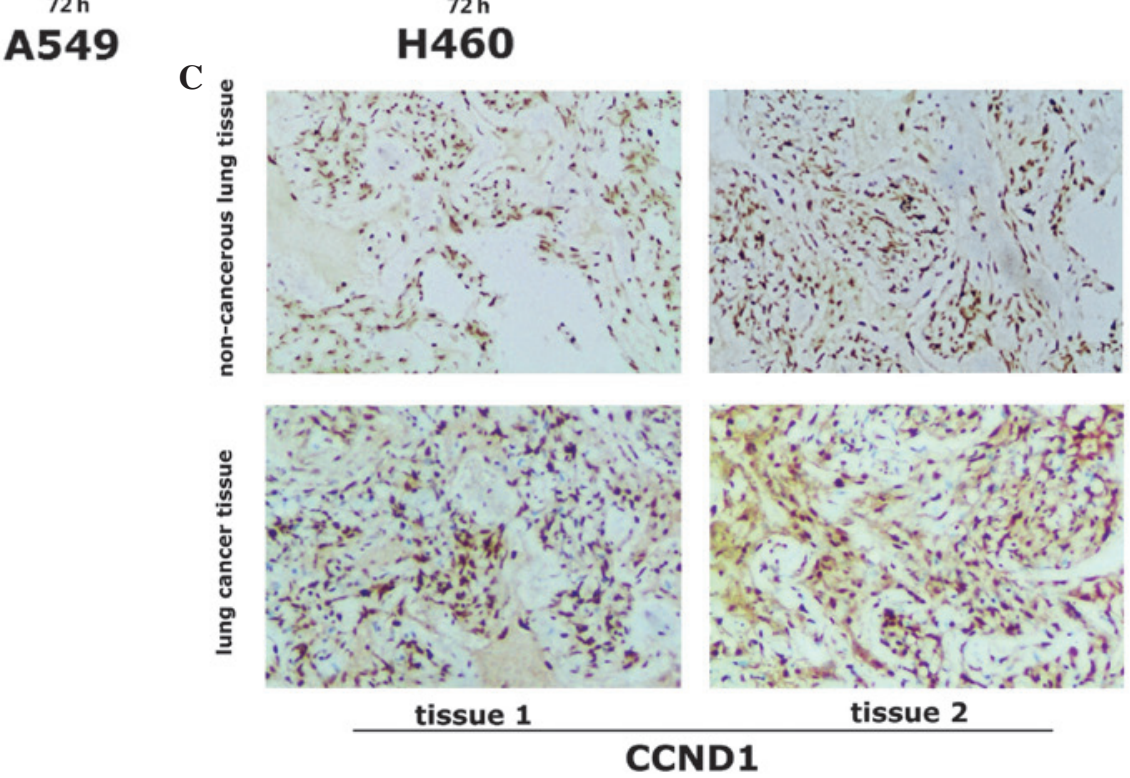

Figure 4. (A) Western blot analysis indicated that CCND1 protein in human lung carcinoma A549 and H460 cells was downregulated significantly $72 \mathrm{~h}$ following the addition of miR-4458 mimics ( ${ }^{* *} \mathrm{P}<0.01$ vs. scramble miR). (B) The expression of CCND1 in the A549 and H460 cells did not alter $24 \mathrm{~h}$ subsequent to the addition of the miR-4458 mimics. The expression of the CCND1 protein was downregulated after $48 \mathrm{~h}$. (C) Immunohistochemistry was used to detect the expression of the CCND1 protein in lung cancer tissue and para-carcinoma tissue of the patients. A representative sample shows that the expression level of CCND1 in lung cancer was increased compared with the para-carcinoma tissue. Magnification, x400. miR, microRNA; CCND1, cyclin D1.
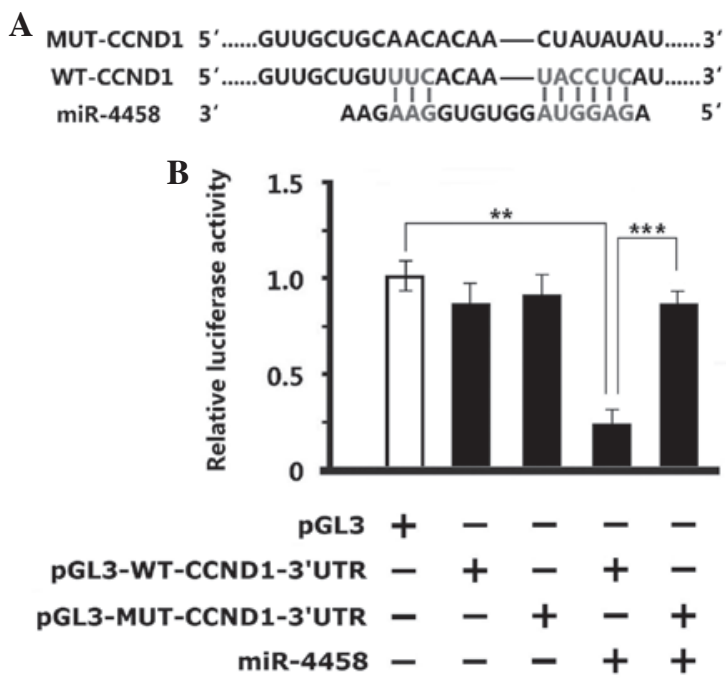

Figure 5. (A) miR-4458 had 9 sequences consistent with WT-CCND1-3'UTR. (B) MUT-CCND1 disrupted the 9 base sequences, and a luciferase reporter assay in human embryonic epithelial $293 \mathrm{~T}$ cells indicated that there were no significant alterations in pGL3M-MUT-CCND1-3'UTR and pGL3M-WT-CCND1-3'UTR in the negative control group compared with pGL3 $\mathrm{M}$ in the vacant plasmid group. There were no significant alterations in viability in the MUT group while the fluorescence intensity in the WT group decreased significantly following addition of miR-4458 mimics $\left({ }^{* *} \mathrm{P}<0.01\right.$; $\left.{ }^{* * *} \mathrm{P}<0.001\right)$. miR, microRNA, CCND1, cyclin D1; WT, wild-type; MUT, mutant; UTR, untranslated region. in the expression of miRs between lung cancer and paracarcinoma tissue in combination with $\mathrm{qPCR}$ verification. These results indicate that miR-4458 may have a specific role in the proliferation and progression of lung cancer. The present study additionally revealed that miR-4458 inhibits the proliferation of lung cancer cells to a greater extent in the lung carcinoma A549 and H460 cell lines. The present study demonstrated, using cell cycle assays, that miR-4458 is capable of causing arrest of the cell cycle at stage G0/G1, and therefore, inhibiting the proliferation of cells (34). The present study used TargetScan software to predict the target gene of miR-4458; the software provided several hundred results. Considering that miRs function by inhibiting target genes, the present study focused on genes relevant to cell cycle and apoptosis. Based on western blot analysis, the present results demonstrated that miR-4458 is capable of inhibiting the expression of CCND1 at the protein level, which confirms that CCND1 is a target gene of miR-4458 (35). In the present study, double reporter experiments have also demonstrated this result. Overall, miR-4458 may participate in inhibiting the onset of lung cancer, as a cancer suppressor gene.

CCND1 protein is encoded by the human CCND1 gene (36). CCND1 is important in controlling the cell growth cycle, and numerous types of cancer abnormally express CCND1 proteins at a high level to stimulate cell growth (37). 
Previous studies have indicated that these proteins may be a fatal characteristic of cancerous cells, since CCND1 inhibitors halt tumor growth and cause cancer cell death $(38,39)$. In addition, studies have revealed that the inhibition of cyclin D1 induces aging of breast cancer cells in mice and inhibition of CCND3 induces apoptosis of cancerous cells of leukemic mice (40). Scientists have identified that CCND inhibitor drugs also have similar effects on human blood tumor cells (41). This protein controls the cell cycle and regulates cell growth and division. In numerous types of cancer, excessive cell cycle proteins allow for fast growth of tumor cells $(42,43)$. It has been demonstrated that abnormal CCND1 is present in breast, lung, endometrial, pancreatic and testicular cancer, multiple myeloma and other types of blood cancer (44-48). Mutation, amplification and over-expression of CCND1 may alter the cell cycle process. These phenomena frequently occur in numerous types of cancer and may cause the development of tumors (49). The present study hypothesizes that miR-4458 may be developed and utilized in the future as a miR drug for the treatment of cancer.

In conclusion, the present study indicates that miR-4458 effectively inhibits migration, proliferation and the cell cycle of lung tumor cells, as well as inhibiting CCND1 expression. The present results provide a novel clue for a deeper understanding of the association between miRs and the incidence of lung cancer, and provide a novel hypothesis and basis for seeking potential molecular targets. The cell cycle specificity of miR-4458 provides a novel direction for developing drugs for blocking cell cycle stage G0/G1 of tumor cells.

\section{Acknowledgements}

The present study was supported by the Project of Incentive Funds for Guidance of Scientific and Technical Innovation in Inner Mongolia Autonomous Region (grant no. 2014CZTCXYD), the National Natural Science Foundation of China (grant no. 81260571), the Public Health Project of The State Administration of Traditional Chinese Medicine (grant no. GJZYYGLJ 11 AGL NZD) and the Public Health Project of The State Administration of Traditional Chinese Medicine (grant no. GJZYYGLJ 11 AGL).

\section{References}

1. Stepanenko AA and Dmitrenko VV: HEK293 in cell biology and cancer research: Phenotype, karyotype, tumorigenicity, and stress-induced genome-phenotype evolution. Gene 569: 182-190, 2015.

2. Ma MZ, Li CX, Zhang Y, Weng MZ, Zhang MD, Qin YY, Gong W and Quan ZW: Long non-coding RNA HOTAIR, a c-Myc activated driver of malignancy, negatively regulates miRNA-130a in gallbladder cancer. Mol Cancer 13: 156, 2014.

3. Verma M, Khoury MJ and Ioannidis JP: Opportunities and challenges for selected emerging technologies in cancer epidemiology: Mitochondrial, epigenomic, metabolomic and telomerase profiling. Cancer Epidemiol Biomarkers Prev 22: 189-200, 2013.

4. Zhang L, Wei P, Shen X, Zhang Y, Xu B, Zhou J, Fan S, Hao Z, Shi H, Zhang X, et al: MicroRNA expression profile in penile cancer revealed by next-generation small RNA sequencing. PloS One 10: e0131336, 2015.

5. Mo W, Zhang J, Li X, Meng D, Gao Y, Yang S, Wan X, Zhou C, Guo $\mathrm{F}$ and Huang Y, et al: Identification of novel AR-targeted microRNAs mediating androgen signalling through critical pathways to regulate cell viability in prostate cancer. PLoS One 8: e56592, 2013.
6. Hsiao SH, Chung CL, Lee CM, Chen WY, Chou YT, Wu ZH, Chen YC and Lin SE: Suitability of computed tomography-guided biopsy specimens for subtyping and genotyping of non-small-cell lung cancer. Clin Lung Cancer 14: 719-725, 2013.

7. Ramnath N, Dilling TJ, Harris LJ, Kim AW, Michaud GC, Balekian AA, Diekemper R, Detterbeck FC and Arenberg DA: Treatment of stage III non-small cell lung cancer: Diagnosis and management of lung cancer, 3rd ed: American College of Chest Physicians evidence-based clinical practice guidelines. Chest 143 (Suppl 5): e314S-e340S, 2013.

8. Zhong KZ, Chen WW, Hu XY, Jiang AL and Zhao J: Clinicopathological and prognostic significance of microRNA-107 in human non small cell lung cancer. Int J Clin Exp Pathol 7: 4545-4551, 2014.

9. Chatterjee A, Chattopadhyay D and Chakrabarti G: miR-17-5p downregulation contributes to paclitaxel resistance of lung cancer cells through altering beclin1 expression. PLoS One 9: e95716, 2014

10. Okudela K, Tateishi Y, Umeda S, Mitsui H, Suzuki T, Saito Y, Woo T, Tajiri M, Masuda M, Miyagi Y and Ohashi K: Allelic imbalance in the miR-31 host gene locus in lung cancer-its potential role in carcinogenesis. PLoS One 9: e100581, 2014.

11. Liu B, Wu X, Liu B, Wang C, Liu Y, Zhou Q and Xu K: miR-26a enhances metastasis potential of lung cancer cells via AKT pathway by targeting PTEN. Biochim Biophys Acta 1822: 1692-1704, 2012.

12. Zhang Z, Zhang L, Yin ZY,Fan XL, Hu B, Wang LQ and Zhang D: miR-107 regulates cisplatin chemosensitivity of A549 non small cell lung cancer cell line by targeting cyclin dependent kinase 8 . Int J Clin Exp Pathol 7: 7236-7241, 2014.

13. Takahashi Y, Forrest AR, Maeno E, Hashimoto T, Daub CO and Yasuda J: miR-107 and miR-185 can induce cell cycle arrest in human non small cell lung cancer cell lines. PLoS One 4: e6677, 2009.

14. Zhou C, Chen H, Han L, Wang A and Chen LA: Identification of featured biomarkers in different types of lung cancer with DNA microarray. Mol Biol Rep 41: 6357-6363, 2014.

15. Jakopovic M, Thomas A, Balasubramaniam S, Schrump D, Giaccone $\mathrm{G}$ and Bates SE: Targeting the epigenome in lung cancer: Expanding approaches to epigenetic therapy. Front Oncol 3: 261, 2013.

16. Gray BP, McGuire MJ and Brown KC: A liposomal drug platform overrides peptide ligand targeting to a cancer biomarker, irrespective of ligand affinity or density. PloS One 8: e72938, 2013.

17. Gao CZ, Zhang Y, Chen J, Fei F, Wang TS, Yang B, Dong P and Zhang YJ: Research progress of the drug delivery system of antitumor platinum drugs with macrocyclic compounds. Yao Xue Xue Bao 50: 650-657, 2015 (In Chinese).

18. Lee WH, Liu HE, Chang JY, Liou JP and Huang HM: MPT0B169, a new tubulin inhibitor, inhibits cell growth and induces G2/M arrest in nonresistant and paclitaxel-resistant cancer cells. Pharmacology 92: 90-98, 2013.

19. Gailhouste L, Gomez-Santos L and Ochiya T: Potential applications of miRNAs as diagnostic and prognostic markers in liver cancer. Front Biosci (Landmark Ed) 18: 199-223, 2013.

20. Song T, Zhang X, Yang G, Song Y and Cai W: Decrement of miR-199a-5p contributes to the tumorigenesis of bladder urothelial carcinoma by regulating MLK3/NF- $\kappa \mathrm{B}$ pathway. Am J Transl Res 7: 2786-2794, 2015.

21. Fesler A, Xu X, Zheng X, Li X, Jiang J, Russo JJ and Ju J: Identification of miR-215 mediated targets/pathways via translational immunoprecipitation expression analysis (TrIP-chip). Oncotarget 6: 24463-24473, 2015.

22. Ochieng J, Ecuru J, Nakwagala F and Kutyabami P: Research site monitoring for compliance with ethics regulatory standards: Review of experience from Uganda. BMC Med Ethics 14: 23, 2013.

23. Marchetti D, Spagnolo A, Cicerone M, Cascini F, La Monaca G and Spagnolo AG: Research ethics committee auditing: The experience of a university hospital. HEC Forum 25: 257-268, 2013.

24. Jhun BW, Lee KJ, Jeon K, Suh GY, Chung MP, Kim H, Kwon OJ, Sun JM, Ahn JS, Ahn MJ, et al: Clinical applicability of staging small cell lung cancer according to the seventh edition of the TNM staging system. Lung Cancer 81: 65-70, 2013.

25. Lee DS, Kim YS, Kay CS, Kim SH, Yeo CD, Kim JW, Kim SJ, Kim YK, Ko YH, Kang JH and Lee KY: Distinctive patterns of initially presenting metastases and clinical outcomes according to the histological subtypes in stage IV non-small cell lung cancer. Medicine (Baltimore) 95: e2795, 2016. 
26. Sokolenko S and Aucoin MG: A correction method for systematic error in (1)H-NMR time-course data validated through stochastic cell culture simulation. BMC Syst Biol 9: 51, 2015.

27. Ying H, Lyu J, Ying T, Li J, Jin S, Shao J, Wang L and Xu H: Risk miRNA screening of ovarian cancer based on miRNA functional synergistic network. J Ovarian Res 7: 9, 2014.

28. Kumarathasan P, Breznan D, Das D, Salam MA, Siddiqui Y, Mackinnon-Roy C, Guan J, de Silva N, Simard B and Vincent R: Cytotoxicity of carbon nanotube variants: A comparative in vitro exposure study with A549 epithelial and J774 macrophage cells. Nanotoxicology 9: 148-161, 2015.

29. Bao L, Zhao J, Dai X, Wang Y, Ma R, Su Y, Cui H, Niu J, Bai S, Xiao Z, et al: Correlation between miR-23a and onset of hepatocellular carcinoma. Clin Res Hepatol Gastroenterol 38: 318-330, 2014.

30. Ji H, Yang Z, Jiang W, Geng C, Gong M, Xiao H, Wang Z and Cheng L: Antiviral activity of nano carbon fullerene lipidosome against influenza virus in vitro. J Huazhong Univ Sci Technolog Med Sci 28: 243-246, 2008.

31. Livak and Schmittgen: Analysis of relative gene expression data using real-time quantitative PCR and the 2- $\Delta \Delta \mathrm{Ct}$ method. Methods 25: 402-408, 2001.

32. Liu XH, Sun M, Nie FQ, Ge YB, Zhang EB, Yin DD, Kong R, $\mathrm{Xia} \mathrm{R}$, Lu KH, Li JH, et al: Lnc RNA HOTAIR functions as a competing endogenous RNA to regulate HER 2 expression by sponging miR-331-3p in gastric cancer. Mol Cancer 13: 92, 2014

33. Paul S and Giri AK: Epimutagenesis: A prospective mechanism to remediate arsenic-induced toxicity. Environ Int 81: 8-17, 2015.

34. Yu X, Song H, Xia T, Han S, Xiao B, Luo L, Xi Y and Guo J: Growth inhibitory effects of three miR-129 family members on gastric cancer. Gene 532: 87-93, 2013.

35. Du B, Wang Z, Zhang X, Feng S, Wang G, He J and Zhang B: MicroRNA-545 suppresses cell proliferation by targeting cyclin D1 and CDK4 in lung cancer cells. PLoS One 9: e88022, 2014.

36. Li Z, Li X, Li C, Su Y, Fang W, Zhong C, Ji W, Zhang Q and Su C: Transcription factor OCT4 promotes cell cycle progression by regulating CCND1 expression in esophageal carcinoma. Cancer Lett 354: 77-86, 2014.

37. Wong L, Power N, Miles A and Tropepe V: Mutual antagonism of the paired-type homeobox genes, vsx 2 and $\mathrm{dmbx} 1$, regulates retinal progenitor cell cycle exit upstream of cond1 expression. Dev Biol 402: 216-228, 2015.

38. Komori $\mathrm{T}$ : Regulation of $\mathrm{Rb}$ family proteins by $\mathrm{Cdk} 6 / \mathrm{Ccnd} 1$ in growth plates. Cell Cycle 12: 2161-2162, 2013.
39. Junk DJ, Cipriano R, Stampfer M and Jackson MW: Constitutive CCND1/CDK2 activity substitutes for p53 loss, or MYC or oncogenic RAS expression in the transformation of human mammary epithelial cells. PLoS One 8: e53776, 2013.

40. Jensen LB, Bartlett JM, Witton CJ, Kirkegaard T, Brown S, Müller S, Campbell F, Cooke TG and Nielsen KV: Frequent amplifications and deletions of G1/S-phase transition genes, CCND1 and MYC in early breast cancers: A potential role in G1/S escape. Cancer Biomark 5: 41-49, 2009.

41. Choi YJ, Li X, Hydbring P, Sanda T, Stefano J, Christie AL, Signoretti S, Look AT, Kung AL, von Boehmer H and Sicinski P: The requirement for cyclin $\mathrm{D}$ function in tumor maintenance. Cancer Cell 22: 438-451, 2012.

42. Liu X, Lv XB, Wang XP, Sang Y, Xu S, Hu K, Wu M, Liang Y, Liu P, Tang J, et al: MiR-138 suppressed nasopharyngeal carcinoma growth and tumorigenesis by targeting the CCND1 oncogene. Cell Cycle 11: 2495-2506, 2012.

43. Cao L, Li C, Shen S, Yan Y, Ji W, Wang J, Qian H, Jiang X, Li Z, Wu M, et al: OCT4 increases BIRC5 and CCND1 expression and promotes cancer progression in hepatocellular carcinoma. BMC Cancer 13: 82, 2013.

44. Zhong Z, Yeow WS, Zou C, Wassell R, Wang C, Pestell RG, Quong JN and Quong AA: Cyclin D1/cyclin-dependent kinase 4 interacts with filamin A and affects the migration and invasion potential of breast cancer cells. Cancer Res 70: 2105-2114, 2010.

45. Achiwa Y, Hasegawa K and Udagawa Y: Effect of ursolic acid on MAPK in cyclin D1 signaling and RING-type E3 ligase (SCF E3s) in two endometrial cancer cell lines. Nutr Cancer 65: 1026-1033, 2013.

46. Wang JC, Thiere M, Henne-Bruns D, Knippschild U and Kornmann M: Inhibition of pancreatic cancer cell growth in vivo using a tetracycline-inducible cyclin D1 antisense expression system. Pancreas 42: 141-148, 2013.

47. Schonbrunn E, Betzi S, Alam R, Martin MP, Becker A, Han H, Francis R, Chakrasali R, Jakkaraj S, Kazi A, et al: Development of highly potent and selective diaminothiazole inhibitors of cyclin-dependent kinases. J Med Chem 56: 3768-3782, 2013.

48. Sewify EM, Afifi OA, Mosad E, Zaki AH and El Gammal SA: Cyclin D1 amplification in multiple myeloma is associated with multidrug resistance expression. Clin Lymphoma Myeloma Leuk 14: 215-222, 2014.

49. Ikeda Y, Oda K, Hiraike-Wada O, Koso T, Miyasaka A, Kashiyama T, Tanikawa M, Sone K, Nagasaka K, Maeda D, et al: Cyclin D1 harboring the T286I mutation promotes oncogenic activation in endometrial cancer. Oncol Rep 30: 584-588, 2013. 